\title{
Fatigue damage detection of CFRP using the electrical resistance change method
}

\author{
Akira Todoroki*, Yoshihiro Mizutani** and Yoshiro Suzuki*** \\ Department of Mechanical Sciences and Engineering, Tokyo Institute of Technology, 2-12-1, Ookayama, Meguro, Tokyo, Japan \\ Daichi Haruyama**** \\ Graduate student of Tokyo Institute of Technology, Department of Mechanical Sciences and Engineering, Tokyo Institute of \\ Technology, 2-12-1, Ookayama, Meguro, Tokyo, Japan
}

\begin{abstract}
Electrical resistance change measurements were performed, to detect fatigue damage of a quasi-isotropic CFRP and cross-ply CFRP laminates. A four-probe method was used to measure the exact electrical resistance change. A three-probe method was used to measure the electrical contact resistance change, during long cyclic loading. The specimen side surface was observed using a video-microscope to detect damage. The measured electrical resistance changes were compared with the observed damage. The results of this study show that the electrical resistance increase of the quasi-isotropic laminate was caused by a delamination crack between $\pm 45^{\circ}$ plies. Matrix cracking caused a small electrical resistance increase of the cross-ply laminate, but the decreased electrical resistance caused by the shear-plastic deformation impedes matrix-cracking detection.
\end{abstract}

Key words: Composites, Electrical resistance, Carbon Fibers, Delamination

\section{Introduction}

The electrical resistance change of carbon fiber reinforced polymer (CFRP) composites is useful information to monitor damage initiation. Many researchers have adopted the electrical resistance change method to detect several kinds of damage in CFRP composites [1-23].

Schulte et al. [1] measured electrical resistance changes of coupon specimens during tensile tests using a two-probe method: two electrical probes are made at both ends of the specimen, to apply electric current, and to measure electric voltage change. Wang and Chung [4] adopted a four-probe method, to cancel the electrical contact resistance at the specimen electrodes. The outer couple of electrodes is used to apply electric current. The inner couple of electrodes are used to measure electrical voltage change. Irving et al. [6] and Seo et al. [7] used the electrical resistance change method to detect fatigue damage in a unidirectional CFRP, and in a crossply CFRP. De Baere et al. [15] used the electrical resistance method for fatigue damage detection in woven fabric CFRP composites.

An earlier report in the literature described cyclic loading tests performed with low applied strain, to prevent fatigue damage in CFRP specimens [24]. Cyclic loading tests of the quasi-isotropic laminate with low applied strain showed a decrease of electrical resistance in the specimens. The decreased electrical resistance was caused by the shear-plastic deformation of the $\pm 45^{\circ}$ plies: plastic deformation of the $\pm 45^{\circ}$ plies during cyclic loading causes shrinkage of thickness; then the thickness reduction increases electrical conductance in the thickness direction, in the same way that a dent does [23].

In this study, cyclic loading tests were performed at a higher applied strain, to elucidate fatigue damage in the quasiisotropic laminate and the cross-ply laminate specimens,
This is an Open Access article distributed under the terms of the Creative Commons Attribution Non-Commercial License (http://creativecommons.org/licenses/by$\mathrm{nc} / 3.0 /$ which permits unrestricted non-commercial use, distribution, and reproduction in any medium, provided the original work is properly cited.

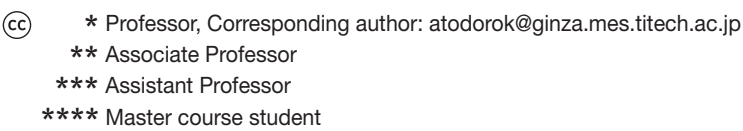


using electrical resistance changes. Specimen side surfaces were carefully observed, using a video-microscope. The electrical resistance changes were measured using the fourprobe method. The measured electrical resistance changes were compared with the observed damage. Finite Element Method (FEM) analyses of the electric current density were performed, to investigate the relation between the observed damage and the electrical resistance changes.

\section{Experimental method}

\subsection{Specimens and fatigue test method}

The material used in the experiments is a unidirectional prepreg sheet (PYROFIL\#380). The stacking sequences are quasi-isotropic [0/45/-45/90]S and cross-ply $\left[0_{2} / 90_{2}\right]$ S. Plates of $250 \mathrm{~mm}$ length, $150 \mathrm{~mm}$ width, and $1.7 \mathrm{~mm}$ thickness were produced using an autoclave. The pre-cure conditions were $85^{\circ} \mathrm{C} \times 2 \mathrm{hr}$. The main curing conditions were $135^{\circ} \mathrm{C} \times$ $3 \mathrm{hr}$ under 0.7 MPa pressure. After curing, the fiber volume fraction $V_{f}$ was measured, using the resin burn-off method. The measured $V_{f}$ was $67 \%$. From the CFRP plates, rectangular plate specimens of $230 \mathrm{~mm}$ length and $12.5 \mathrm{~mm}$ width were produced, as presented in Fig. 1. On one side of the specimen surface, four copper electrodes of $5 \mathrm{~mm}$ width were affixed, using the copper plating method described in an earlier report [18]. After producing the electrodes, the specimens were kept in a muffle furnace at $50^{\circ} \mathrm{C}$ for $20 \mathrm{hr}$, to prevent the effects of moisture absorption.

To measure the electrical resistance of the specimen, the four-probe method was adopted, and an LCR meter (3522; Hioki E. E. Corp., Japan) was used. For measurements, alternating current of $450 \mathrm{~Hz}$ of $30 \mathrm{~mA}$ was applied. The impedance using the alternating current was measured. Because the phase angle of the measured impedances was zero, the measured impedance was regarded as an electrical resistance in this study. To measure the electrical contact resistance at the electrode, a three-probe method was applied. The difference between the four-probe method and the three-probe method is described in section 2.2 and the reference [24].

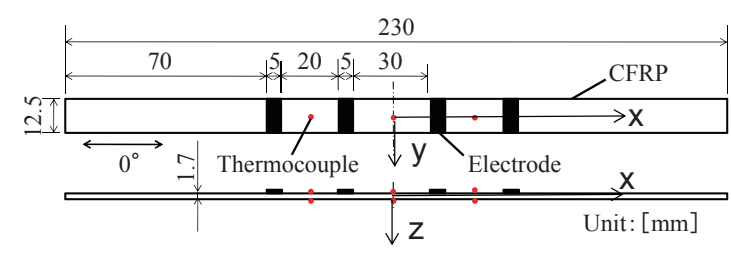

Fig. 1. Specimen configuration.
K-type thermocouples were used to measure specimen temperatures. At the middle between the electrodes, the K-type thermocouples were mounted in the positions shown by dots in Fig. 1. The variation of the measured temperature of the six points was kept within $\pm 1^{\circ} \mathrm{C}$ during the cyclic loading test. Because the temperature effect is extremely small, temperature change compensation was not performed.

For the cyclic loading test, a closed-loop hydrostatic servomaterial-testing machine was used. Tension-tension cyclic loading tests of stress ratio $R=0.1$ were performed for this study. The applied maximum strain for the quasi-isotropic specimen was $4,200 \mu$, which is $30 \%$ of the tensile fracture strain (fracture stress is $695 \mathrm{MPa}$ ). The frequency was $30 \mathrm{~Hz}$. A sine wave was used for the loading pattern. The maximum number of cycles used for this experiment was $10^{7}$. The cyclic loading strain of the cross-ply laminate was also set to the same value as the quasi-isotropic specimen. As most of the electric current flows in the surface $0^{\circ}$-plies, the magnitude of electric resistance change ratios $\left(\Delta R / R_{0}: \Delta R\right.$ is the electrical resistance change and $R_{0}$ is the reference electric resistance) of the two kinds of the specimens are almost the same, when the applied strain of the surface $0^{\circ}$-plies is set to the same level. This is because the electrical resistance change is controlled by the applied strain, but not the applied stress, as described in a report of an earlier study [22].

\subsection{Four-probe method, and three probe method}

The four-probe method and the three-probe method are presented in Fig. 2. When the outer couple of electrodes (\#1 and \#4) were used to apply electric current, and the inner couple of electrodes (\#2 and \#3) were used to measure the voltage change (the relay circuit is switched to line " $a$ " in Fig. 2), the measurement method is the four-probe method. When the electrical resistance of the voltage meter is at its highest (in the order of $\mathrm{M} \Omega$ ), the electrical current flowing in the voltage meter is negligibly small, because the electrical resistance of the CFRP specimen is approximately smaller than $1 \Omega$, which enables the electrical resistance $(R)$ to be measured independently of the electrode contact resistance ( $r$ ) using the four-probe method.

In this study, the electrical resistance $(R)$ of the specimen

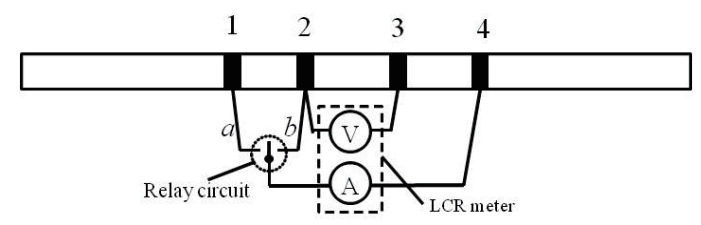

Fig. 2. Four-probe method and three-probe method to measure the contact resistance at the electrodes. 
is first measured using the four-probe method. Subsequently the four-probe circuit is switched to the three-probe circuit (switched from line " $a$ " to line " $b$ "), as presented in Fig. 2. The three-probe method includes the contact resistance $(r)$ at one electrode (here, \#2 is used as the electrode to apply electric current, and to measure the voltage change). The electrical resistance measured using the three-probe method is therefore $(R+r)$. Subtraction of $(R)$ from $(R+r)$ yields the contact resistance $(r)$. This method enables both $(R)$ and $(r)$ to be measured, using an automatic relay switch circuit, as shown in Fig. 2.

All of the measured electric resistance change $\Delta R$ $\left(\Delta R=R-R_{0}\right)$ is normalized by the reference electrical resistance $\mathrm{R}_{0}$, which is the electrical resistance measured at $10^{2}$ cycles, to prevent the effect of the electrical resistance difference between specimens .

\section{Results and Discussion}

Figure 3 shows the experimentally obtained results of electrical resistance change, during cyclic loading of the quasi-isotropic specimen. The abscissa shows the number of cycles. The ordinate shows the measured electric resistance change using the four-probe method. Similar to the electrical resistance change of the low applied strain in the previous paper [24], the electrical resistance decreases

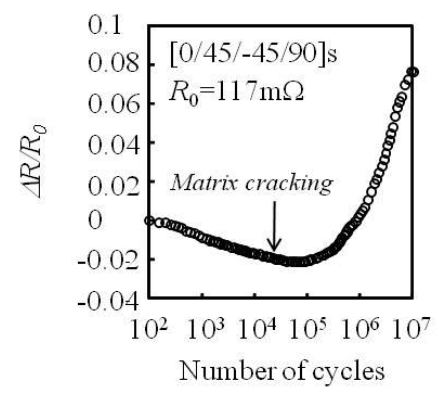

Fig. 3. Electrical resistance change during cyclic loading of $[0 / \pm 45 / 90] \mathrm{s}$.

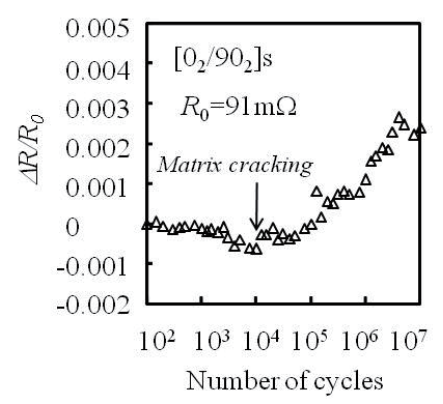

Fig. 4. Electrical resistance change during cyclic loading of $\left[\mathrm{O}_{2} / 9 \mathrm{O}_{2}\right] \mathrm{s}$. with the increase of the number of cycles, up to $4 \times 10^{4}$ cycles. Beyond $4 \times 10^{4}$ cycles, however, the electrical resistance starts to increase.

Figure 4 shows the experimentally obtained results of electrical resistance change, during cyclic loading of the cross-ply specimen. Similar to the electrical resistance change of the low applied strain in the previous paper [24], the electrical resistance is almost constant with the increase of the number of cycles, before $1 \times 10^{4}$ cycles. After $1 \times 10^{4}$ cycles, the electrical resistance starts to increase.

Figure 5 shows the specimen side surface observed at the cycles of the damage initiation. As shown in the circles in the figure, a matrix crack is observed in the $90^{\circ}$-ply. As portrayed in Fig. 4, the matrix cracking seems to start at the increase of electrical resistance of the cross-ply laminate. In contrast, no electrical resistance increase of the quasi-isotropic laminate is observed at $2 \times 10^{4}$ cycles in Fig. 3 .

Figure 6 presents observations of the specimen side surface of the quasi-isotropic laminate at the number of cycles of $4 \times 10^{4}$. The delamination cracks and matrix cracks are visible in Fig. 6, as shown in circles. As depicted in Fig. 3 , the electrical resistance of the quasi-isotropic laminate increases from approximately $4 \times 10^{4}$ cycles. Therefore, the electrical resistance of the quasi-isotropic laminate indicates delamination cracking.

The magnitude of the electrical resistance change between the quasi-isotropic laminate and the cross-ply laminate can be compared, as shown in Figs. 3 and 4. The initial decrease of the electrical resistance change ratio of the quasi-isotropic

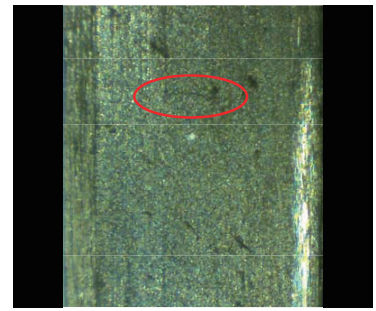

$[0 / \pm 45 / 90] \mathrm{s}, 2 \times 10^{4}$ Cycles

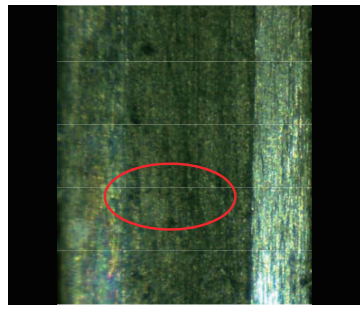

$\left[0_{2} / 90_{2}\right] \mathrm{s}, 1 \times 10^{4}$ Cycles
Fig. 5. Specimen side surface at crack initiation.

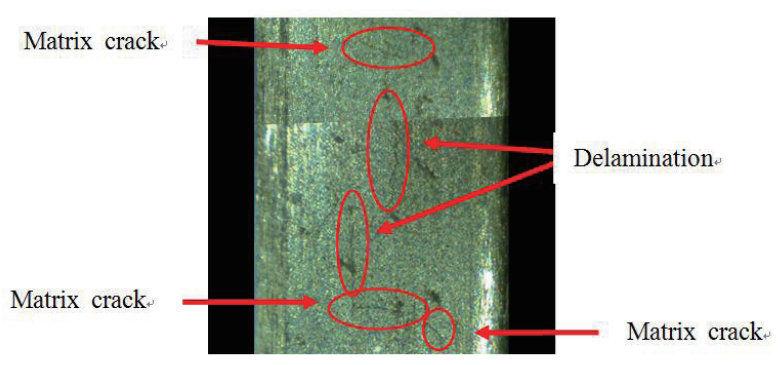

Fig. 6. Delamination initiation of $[0 / \pm 45 / 90] s$. 
laminate (in Fig. 3) comes from the decrease of thickness caused by the in-plane shear plastic deformation in the $\pm 45^{\circ}$-plies during tensile loading, as shown in reference [24]. The tensile stress applied in the quasi-isotropic laminate, and the tensile deformation of $\pm 45^{\circ}$-plies includes in-plane shear deformation that has large plastic deformation. For the cross-ply laminate in Fig. 4, the laminate has no angle plies, and that means the laminate has no in-plane shear plastic deformation. This caused no change of $\Delta R / R_{0}$ in the initial cycles of the cross-ply laminate.

Because the reference resistances $R_{0}$ of both laminates are almost identical, the magnitude of the electrical resistance change of the cross-ply laminate is almost one-twentieth of the quasi-isotropic laminate. This small increase of the electrical resistance change in the cross-ply laminate shows that the matrix cracking in the $90^{\circ}$-ply has only a small effect on the electrical resistance change of the cross-ply specimen. Because the electrical resistance of the quasi-isotropic laminate decreases greatly with the increase of the number of cycles, as a result of the shear-plastic deformation of the angle plies, as mentioned previously, electrical resistance change caused by matrix cracking cannot be detected for the quasi-isotropic specimen.

Figure 7 shows the specimen side surface after the number of cycles of $10^{7}$. For the quasi-isotropic specimen, large delamination cracks are visible. For the crossply laminate, many matrix cracks are observed, but no delamination crack is observed. This difference is caused by the difference of applied stress. As the applied cyclic strain of the two different laminates was set to the same value, the applied stresses were different between the two laminates. As the cross-ply includes four of the $0^{\circ}$-plies, the ultimate fracture strength of the cross-ply is higher than that of the quasi-isotropic laminates. This caused the delamination of the quasi-isotropic laminates at this applied strain, and no delamination in the cross-ply laminates. This difference of the damage mechanism also caused the difference of the electrical resistance changes between the quasi-isotropic specimen and the cross-ply specimen. The delamination

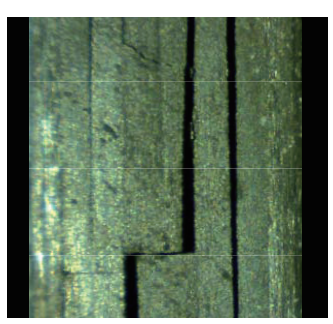

$[0 / \pm 45 / 90] \mathrm{s}$

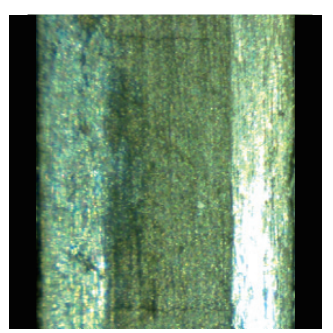

$\left[0_{2} / 90_{2}\right] \mathrm{s}$
Fig. 7. Specimen side surface after fatigue tests. crack caused shut down of the electric current path between the $\pm 45^{\circ}$-plies in the quasi-isotropic laminates, and the absence of delamination in the cross-ply laminates caused only small electrical resistance increase, caused by the matrix cracking.

To investigate the effect of the damage mechanism on the electrical resistance changes, FEM analyses of the electric current density of both types of specimens were performed, using commercially available FEM code ANSYS ver. 12 . Threedimensional FEM analyses were conducted, using a SOLID 226 element of 20 nodes. The material properties used for the FEM analyses were referred from an earlier report [8]. The total number of elements used for the analyses was 7,360. The applied current was $30 \mathrm{~mA}$, which is the same as the actual specimen. Fig. 8 shows the contour plot of the electric current density of the cross section of the specimen middle point: for both specimens, most of the electric current flows in the top surface $0^{\circ}$-ply. In the quasi-isotropic laminate, however, a considerable amount of electric current flows in the angle plies (the second and the third ply). In these angle plies, electric current flows in the fiber direction $\left(+45^{\circ}\right.$ or $-45^{\circ}$ in each ply). The current flows in the thickness direction at the specimen end, and flows in the fiber direction in the other ply, as described in an earlier report in the literature [24]. The large electric current in the thickness direction is impeded by the delamination crack. For that reason, the delamination crack has a strong effect on the electrical resistance change in the quasi-isotropic laminate.

Figures 9 and 10 show the contact-resistance change at the electrode during cyclic loading, measured using the three-probe method. The reference resistances $\left(r_{0}\right)$ are almost identical. Both electrodes are made on the surface $0^{\circ}$ -
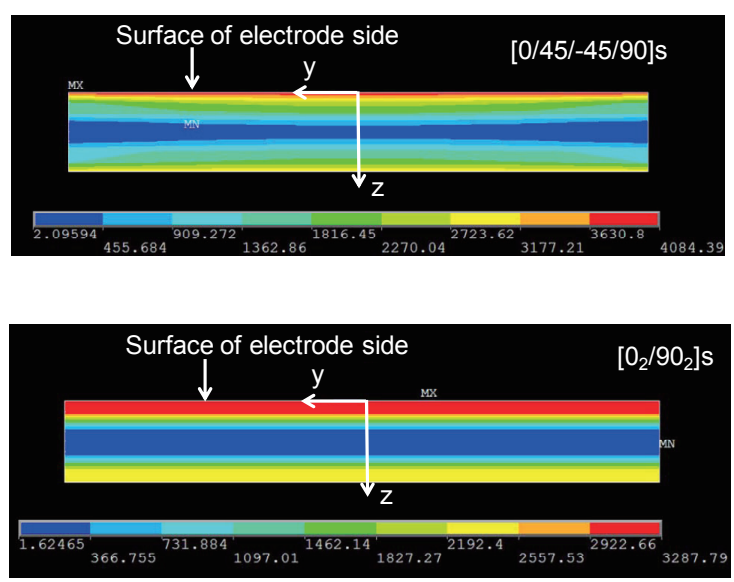

Fig. 8. Electric current density of the specimen longitudinal direction at the middle of the specimen cross section (the top surface is the specimen surface in which the electrodes are made; unit A/ $\left.m^{2}\right)$. 


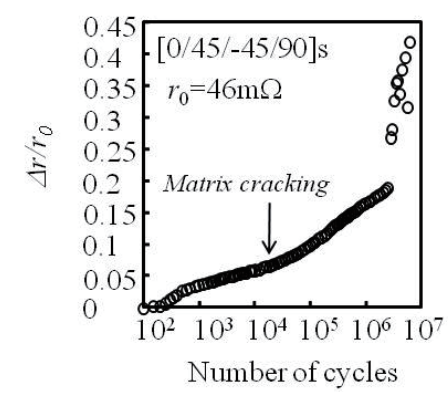

Fig. 9. Change of the contact electrode resistance during cyclic loading of a quasi-isotropic CFRP laminate.

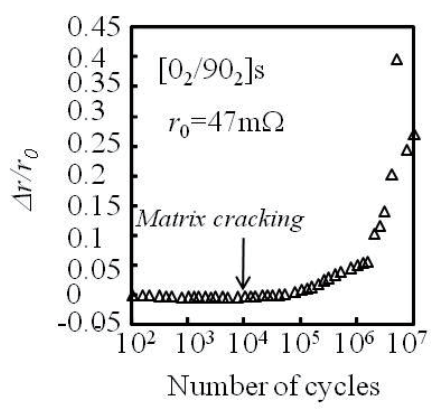

Fig. 10. Change of the contact electrode resistance during cyclic loading of a cross-ply laminate.

ply. The difference of the contact resistance change of both laminates derives from the difference of the deformation of the transverse direction. For the cross-ply laminate, the contact resistance does not change, up to $10^{4}$ cycles. After the initiation of matrix cracking, the contact resistance starts increasing in the cross-ply laminate, which indicates that the damage increases the contact resistance. For the quasi-isotropic specimen, the contact resistance increases from the beginning. The same results were obtained from an earlier study of lower applied strain [24]. For the lower applied load, no damage was found. The increase of the contact resistance of the quasi-isotropic specimen from the beginning indicates that the shear-plastic deformation of the angle ply in the quasi-isotropic laminate causes electrode damage in the quasi-isotropic specimen.

In actual laminates, angle plies are almost always included. Therefore, when the electrodes are made on the laminate surface, the contact resistance of the actual laminates increases. The four-probe method is indispensable for a long-term monitoring system.

\section{Conclusions}

This report described cyclic loading tests of CFRP laminates of a quasi-isotropic laminate and a cross-ply laminate, under high applied strain. Fatigue damage of matrix cracking and delamination cracking were observed at the specimen side surface, using a video-microscope. Electrical resistance changes of the specimens were measured, using the four-probe method. Contact resistance changes were also measured, using the three-probe method. The following results were obtained.

(1) For a quasi-isotropic laminate, matrix cracking in the $90^{\circ}$-ply is undetectable. The in-plane shear plastic deformation of the $\pm 45^{\circ}$-plies caused a significant decrease of the electrical resistance, and this makes it quite difficult to detect the initiation of matrix cracking.

(2) Delamination cracking can be detected by the electrical resistance change for a quasi-isotropic laminate. The delamination crack shut down the electric current path between the $\pm 45^{\circ}$-plies, and this can be detected by the significant increase of the electrical resistance change ratio.

(3) For a cross-ply laminate, matrix cracking is detectable, using the electrical resistance change method. However, the magnitude of the electrical resistance change of the crossply laminate is extremely small, compared with the electrical resistance change caused by delamination cracking in the quasi-isotropic laminate. The electric current in the $90^{\circ}$-ply is very small, compared with that in the $0^{\circ}$-ply and $\pm 45^{\circ}$-plies. This caused small electrical resistance change, by the matrix cracking of the cross-ply laminate. As delamination cracking does not occur in the applied strain level for the crossply laminate, large electrical resistance increase was not observed in the present study.

(4) The contact resistance at the electrodes increases for the quasi-isotropic laminate from the beginning, because of the in-plane shear-plastic deformation of the $\pm 45^{\circ}$-plies. For the $\pm 45^{\circ}$-plies, applied tensile cyclic strain caused plastic deformation, because of the in-plane shear stress. For the quasi-isotropic laminate, this caused increase of the contact resistance at the electrode.

\section{References}

[1] Schulte K., and Baron Ch., "Load and Failure Analyses of CFRP Laminates by Means of Electrical Resistivity Measurements", Composites Science and Technology, Vol.36, Issue 1, 1989, pp. 63-76.

[2] Muto N, Yanagida H, Nakatsuji T, Sugita M, Ohtsuka Y., "Preventing Fatal Fractures in Carbon-Fibre-GlassFibre-Reinforced Plastic Composites by Monitoring Change in Electrical Resistance", Journal of the American Ceramic Society, Vol.76, Issue 4, 1993, pp.875-879. 
[3] Kaddour A. S., Al-Salehi F. A. R., and Al-Hassani S. T. S., "Electrical Resistance Measurement Technique for Detecting Failure in CFRP Materials at High Strain Rate", Composites Science and Technology, Vol.51, Issue 3,1994, pp. 77-385.

[4] Wang X, Chung D.D.L., "Short Carbon Fiber Reinforced Epoxy as a Piezoresistive Strain Sensor", Smart Materials and Structures, Vol.4, Issue 4, 1995, pp. 363-367.

[5] Todoroki A, Matsuura K, Kobayashi H., "Application of Electric Potential Method to Smart Composite Structures for Detecting Delamination", JSME International Journal Series A, Vol.38, No. 4, 1995, pp. 524-530.

[6] Irving PE, Thiagarajan C., "Fatigue Damage Characterization in Carbon Fibre Composite Materials using an Electrical Potential Technique", Smart Materials and Structures, Vol.7, No.4, 1998, pp. 456-466.

[7] Seo D. C., Lee J. J., "Damage Detection of CFRP Laminates using Electrical Resistance Measurement and a Neural Network", Composite Structures, Vol.47, Issue 1-4, 1999, pp. 525-530.

[8] Abry J. C., Choi Y.K, Chateauminois A., Dalloz B., Giraud G., Salviam M., "In-situ Monitoring of Damage in CFRP Laminates by means of AC and DC measurements", Composite Sciences and Technology, Vol.61, Issue 6, 2001, pp. 855-864.

[9] Park J. B., Okabe T., Takeda, N., Curtin W.A., "Electromechanical modeling of unidirectional CFRP composites under tensile loading condition", Composites Part A, Vol.33, Issue 2, 2002, pp. 267-275.

[10] Todoroki A, Tanaka Y, Shimamura Y., "Delamination monitoring of graphite/epoxy laminated composite plate of electric resistance change method", Composites Science and Technology, Vol.62, Issue 9, 2002, pp. 1151-1160.

[11] Todoroki A, Tanaka M, Shimamura Y., "Measurement of orthotropic electric conductance of CFRP laminates and analysis of the effect on delamination monitoring with electric resistance change method", Composite Sciences and Technology, Vol.62, Issue 5, 2002, pp. 619-628.

[12] Ogi K, Takao Y., "Characterization of piezoresistance behavior in a CFRP unidirectional laminate", Composites Science and Technology ,Vol.65, Issue 2, 2005, pp. 231-239.

[13] Angelidis N., Irving P. E., "Detection of impact damage in CFRP laminates by means of electrical potential techniques", Composites Science and Technology, Vol.67, Issue 3-4, 2007, pp. 594-604.

[14] Sevkat E., Liaw B., Delale F., "A Statistical model of electrical resistance of carbon fiber reinforced composites under tensile loading", Composites Science and Technology, Vol.68, Issue 10-11, 2008, pp. 2214-2219.

[15] De Baere I., Van Paepegem W., Degrieck J., “Electrical resistance measurement for in-situ monitoring of fatigue of carbon fabric composites", International Journal of Fatigue, Vol.32, Issue 1, 2010, pp. 197-207.

[16] Todoroki A., Samejima Y., Hirano Y., Matsuzaki R., "Piezoresistivity of Unidirectional Carbon/epoxy Composites for Multiaxial Loading", Composites Science and Technology, Vol.69, Issue 11-12, 2009, pp.1841-1846.

[17] Todoroki A., Samejima Y., Hirano Y., Matsuzaki R., Mizutani Y., "Electrical Resistance Change of Thick CFRP Laminate for Self-Sensing", Journal of Solid Mechanics and Materials Engineering JSME, 2010, Vol. 4, No.6, pp. 658-668.

[18] Todoroki A., Suzuki K., Mizutani Y., Matsuzaki R., "Durability Estimates of Copper Plated Electrodes for Selfsensing CFRP Composites", Journal of Solid Mechanics and Materials Engineering JSME, Vol.4, No.6, 2010, pp. 610-620.

[19] Todoroki A., Suzuki K., Mizutani Y., Matsuzaki R. "Electrical Resistance Change of CFRP under compression load", Journal of Solid Mechanics and Materials Engineering JSME, 2010, Vol. 4, No.7, pp. 864-874.

[20] Suzuki Y., Todoroki A., Mizutani Y., Matsuzaki R., "Impact damage detection in CFRP using statistical analysis of resistance temperature characteristics", Journal of Solid Mechanics and Materials Engineering JSME, Vol.5, No.1, 2011, pp. 33-43.

[21] Todoroki A., "Monitoring of Electric Conductance and Delamination of CFRP Using Multiple Electric Potential Measurements", Advanced Composite Materials, 2013 (In press).

[22] Todoroki A, Yoshida J., "Electrical resistance change of unidirectional CFRP due to applied load", JSME International Journal Series A, Vol.47, No.3, 2004, pp. 357-364.

[23] Todoroki A., Shimazu Y., Mizitani Y., "Electrical resistance reduction of laminated carbon fiber reinforced polymer by dent made by indentation without cracking", Journal of Solid Mechanics and Materials Engineering JSME, Vol.6, No.12, 2012, pp. 1042-1052.

[24] Todoroki A, Haruyama D, Mizutani Y, Suzuki Y, Yasuoka T., "Electrical resistance change of self-sensing CFRP laminate during cyclic loading", Transactions of JSME, Series A, Vol.79, No.803, 2013, pp.1009-1018, (in Japanese). 